\title{
Increased Variance of Quantitative Characters in the Two Types of Gynogenetic Diploids of Indonesian Common Carp
}

\author{
K. Sumantadinata, ${ }^{* 1}$ N. Taniguchi, ${ }^{* 2}$ and Sugiarto*1 \\ (Received May 21, 1990)
}

\begin{abstract}
Gynogenetic diploid induced by retaining second polar body and that by suppressing first cleavage of eggs of Indonesian common carp Cyprinus carpio were produced by inseminating eggs with ultra-violet ray irradiated sperm of Java carp Puntius gonionotus and giving heat shock treatment to the developing eggs. The morphometric and meristic characters of 3 month old fish were measured and counted. There was the prominent trend that the degree of phenotypic variation was larger in the mitotic- and meiotic-gynogenetic diploids than in the control-2N in the almost all morphological characters examined. These phenomena observed in variation of quantitative characters were explained by the function showing the relationship among phenotypic variance $\left(V_{p}\right)$, genetic variance $\left(V_{q}\right)$, environmental variance $\left(V_{\varepsilon}\right)$ and coefficient of inbreeding $(F)$ in the first gynogenetic generation. The genetic implications for gynogenetic diploids were discussed in relation to genetic improvement of fish race in aquaculture.
\end{abstract}

Gynogenetic diploid induced by retaining the second polar body (abbreviated as meiotic-G2N) shows a different level of homozygosity in genotype composition by locus depending upon genecentromere recombination rates. ${ }^{1,2)}$ In rainbow trout, for instance, it is infeasible to produce any line homozygous at all loci and genome by inducing gynogenesis followed by retention of the second polar body. ${ }^{1)}$ However, gynogenesis by suppressing the first cleavage (abbreviated as mitotic$\mathrm{G} 2 \mathrm{~N}$ ) is able to produce offspring showing complete homozygosity both at all loci and genomes in the 1st generation because it is not given any effects of crossing over during meiosis. ${ }^{3-5)}$ Therefore, this method may have an advantage to produce pure lines in the 2 nd generation."

It is expected that the coefficient of inbreeding (F) increases in gynogenetic diploid. ${ }^{\circledR)}$ The genetic variance of quantitative characters will also increase in the first gynogenetic generation according to the formula of variance among inbreeding lines, $(1+F) V_{g}{ }^{n)}$ if the variance among gynogenetic individuals could be considered as analogous with that among the inbreeding lines. Since mitoticG2N takes a maximum value of $F$, it is expected the level of phenotypic variance will be always larger in the mitotic-G2N than in the meioticG2N as ascertained in ayu, Plecoglossus altivelis, ${ }^{8)}$ but the variance will decrease within a family in the second generation of G2Ns. ${ }^{5}$ The variance analysis seemed to be useful for the estimation of heritability based on the degree of increase in genetic variance on the two types of gynogenetic diploid, and may give useful informations for the genetic improvement of fish race. ${ }^{5)}$

In this paper, we estimated the phenotypic variations of some quantitative characters and compared the values of the G2Ns with these of control-2N of Indonesian common carp stock to ascertain the phenomenon of increasing in variation being a remarkable genetic character of $\mathrm{G} 2 \mathrm{Ns},{ }^{5)}$ to assess the degree of heritability in each quantitative character.

\section{Materials and Methods}

Five matured females of Majalaya stock, one of the most important stock in freshwater fish culture in Indonesia, were used to collect eggs for the experiments to induce gynogenetic diploids. A female being about $4 \mathrm{~kg}$ in body weight was given an injection of extract of $3 \mathrm{mg}$ silver carp pituitary gland per $\mathrm{kg}$ body weight of the female to induce ovulation, and then put into the spawning pond together with a few males. Just after the first spawning action being considered as a signal for

*1 Department of Aquaculture, Faculty of Fisheries, Bogor Agricultural University, Kampus IPB Darmaga, Bogor, Indonesia.

*2 Department of Cultural Fisheries, Faculty of Agriculture, Kochi University, B200 Monobe, Nankoku, Kochi 783, Japan (谷口順彦: 高知大学臀学部伐培漁業学科). 
complete ovulation which is usually observed early in the morning, the female was transfered to the laboratory for egg collection by stripping the belly. The sperm from a male of java carp (tawes), Puntius gonionotus, was irradiated with ultraviolet light by the method of Taniguchi et $a l .{ }^{8}{ }^{8}$ and used for inseminating the common carp eggs. The initial time to heat shocking applied were 2 to $4 \mathrm{~min}$ after immersion of the eggs in the water temperature $25^{\circ} \mathrm{C}$ for induction of meioticG2N and 40 to 44 min for induction of mitoticG2N. We applied heat shocking for $1.5 \mathrm{~min}$ at $40^{\circ} \mathrm{C}$. The eggs were incubated in $80 l$ aquaria with recirculating system. The water temperature was $24-25^{\circ} \mathrm{C}$. The recirculating system was stopped a few hours before hatchingout. As for the detailed procedures and verification of succesfulness of gynogenesis in Indonesian common carp see Sumantadinata, et al. ${ }^{11)}$ The hatched fry were fed artemia nauplii for about ten days.

The two week old fry were transfered into $100 l$ concrete tanks with a double bottom and airlift system. ${ }^{12)}$ The density was 50 fry per tank for the first month, then the density was lowered to 25 fry per tank for the second and third months. During the first month rearing, the fry were fed moina, daphnia and the shrimp feed. In the second and third month, the fish were fed three times daily with larger sized shrimp feed and fresh tubifex worm.

The three month old fish were taken for meas- urements and counts for morphological characters. The number of samples from the 5 experiments are presented in Table 1. The following morphometric and meristic characters were measured and counted: the relative values of body depth, body width, head length and intestine length to standard length, and the numbers of vertebrae, lateral line scales, gill rakers on the first gill arch, soft rays of dorsal, pectoral, ventral and anal fins.

The means and coefficients of variation of these morphometric and meristic characters were calculated for each experiment and for the pooled of all the five exeriments. Meristic characters of the female parents were also counted.

\section{Results}

\section{Variation in morphometric characters}

The body sizes of gynogenetic offsprings at 3 month old were not different significantly from that of the control-2 $\mathrm{N}$ as shown in the mean values of standard length in each experiment (Table 1). However, there was a trend that the coefficients of variation in body size were always greatest in the mitotic-G2N, followed by meiotic-G2N, and smallest in the control-2N.

The means and coefficients of variation for morphometric characters in the five experiments are summarized in Table 2 to compare these values of the two types of $\mathrm{G} 2 \mathrm{~N}$ with that of the control-2N. Mean proportional values of body

Table 1. Number (n) of samples, mean and coefficient of variation (CV) for standard length (cm) of the meiotic-G2N, mitotic-G2N and control-2N from 5 experiments

\begin{tabular}{clccc}
\hline $\begin{array}{c}\text { Experiment } \\
\text { No. }\end{array}$ & & Control-2N & Meiotic-G2N & Mitotic-G2N \\
\hline 1 & $\mathrm{n}$ & 50 & 53 & 11 \\
& Mean & 7.873 & 6.960 & 8.658 \\
& CV $(\%)$ & 8.9 & 9.9 & 17.7 \\
2 & $\mathrm{n}$ & 46 & 39 & 17 \\
& Mean & 8.072 & 6.793 & 8.971 \\
& CV $(\%)$ & 8.6 & 11.4 & 23.5 \\
3 & $\mathrm{n}$ & 53 & 47 & 31 \\
& Mean & 8.492 & 7.239 & 7.976 \\
& CV $(\%)$ & 6.6 & 13.4 & 23.0 \\
4 & $\mathrm{n}$ & 50 & 46 & 17 \\
& Mean & 7.210 & 7.262 & 7.622 \\
& CV (\%) & 12.5 & 17.0 & 19.4 \\
& $\mathrm{n}$ & 50 & 50 & 51 \\
& Mean & 6.657 & 6.722 & 6.921 \\
& CV (\%) & 9.7 & 11.7 & 14.7 \\
\hline
\end{tabular}


Table 2. Mean and coefficient of variation (CV) of relative avlue of morphometric characters to standard length in the control-2N, meioticG2N and mitotic-G2N for 5 experiments

\begin{tabular}{|c|c|c|c|c|c|c|c|c|c|c|c|c|c|}
\hline \multirow{3}{*}{$\begin{array}{l}\text { Types of } \\
\text { offspring }\end{array}$} & \multicolumn{10}{|c|}{ Experiment no. } & \multirow{2}{*}{\multicolumn{3}{|c|}{ Overall population }} \\
\hline & \multicolumn{2}{|c|}{1} & \multicolumn{2}{|c|}{2} & \multicolumn{2}{|c|}{3} & \multicolumn{2}{|c|}{4} & \multicolumn{2}{|c|}{5} & & & \\
\hline & Mean & $\begin{array}{l}\mathrm{CV} \\
(\%)\end{array}$ & Mean & $\begin{array}{l}\mathrm{CV} \\
(\%)\end{array}$ & Mean & $\begin{array}{l}\mathrm{CV} \\
(\%)\end{array}$ & Mean & $\begin{array}{l}\mathrm{CV} \\
(\%)\end{array}$ & Mean & $\begin{array}{l}\mathrm{CV} \\
(\%)\end{array}$ & Mean & $\begin{array}{l}\mathrm{CV} \\
(\%)\end{array}$ & $\mathbf{V}$ \\
\hline \multicolumn{14}{|l|}{ Body depth } \\
\hline $\mathrm{C}-2 \mathrm{~N}$ & 0.40 & 6.0 & 0.40 & 10.0 & 0.39 & 4.0 & 0.41 & 6.0 & 0.40 & 9.0 & 0.40 & 7.0 & 0.00078 \\
\hline Mei-G2N & 0.40 & 8.0 & 0.41 & 6.0 & $0.41^{* *}$ & 7.0 & $0.43^{* *}$ & 9.0 & $0.44^{* *}$ & 9.0 & $0.42^{* *}$ & 8.0 & 0.00113 \\
\hline Mit-G2N & $0.42^{*}$ & 6.0 & $0.44^{*}$ & 8.0 & $0.44 * *$ & 6.0 & $0.47^{* *}$ & 6.0 & $0.44^{* *}$ & 8.0 & $0.44^{* *}$ & 7.0 & 0.00095 \\
\hline \multicolumn{14}{|l|}{ Body width } \\
\hline $\mathrm{C}-2 \mathrm{~N}$ & 0.21 & 8.0 & 0.21 & 11.0 & 0.20 & 7.0 & 0.22 & 6.0 & 0.21 & 8.0 & 0.21 & 8.0 & 0.00028 \\
\hline $\mathrm{Mei-G} 2 \mathrm{~N}$ & $0.22^{* *}$ & 9.0 & $0.22 * *$ & 8.0 & $0.22 * *$ & 16.0 & $0.24^{* *}$ & 10.0 & $0.24^{* *}$ & 8.0 & $0.23^{* *}$ & 10.0 & 0.00053 \\
\hline Mit-G2N & $0.23^{* *}$ & 6.0 & $0.23^{* *}$ & 9.0 & $0.23^{* *}$ & 8.0 & $0.25^{* *}$ & 8.0 & $0.25^{* *}$ & 10.0 & $0.24^{* *}$ & 9.0 & 0.00047 \\
\hline \multicolumn{14}{|l|}{ Head length } \\
\hline $\mathrm{C}-2 \mathrm{~N}$ & 0.35 & 14.0 & 0.35 & 7.0 & 0.35 & 6.0 & 0.38 & 4.0 & 0.37 & 5.0 & 0.36 & 7.0 & 0.00064 \\
\hline Mei-G2N & $0.37^{*}$ & 8.0 & 0.36 & 7.0 & $0.37^{* *}$ & 7.0 & 0.38 & 5.0 & $0.38^{*}$ & 5.0 & $0.37^{* *}$ & 6.0 & 0.00049 \\
\hline Mit-G2N & 0.36 & 5.0 & 0.36 & 8.0 & 0.36 & 9.0 & 0.40 & 20.0 & $0.39 * *$ & 5.0 & $0.38^{* *}$ & 8.0 & 0.00092 \\
\hline \multicolumn{14}{|c|}{ Intestine length } \\
\hline $\mathrm{C}-2 \mathrm{~N}$ & 1.71 & 13.0 & 1.63 & 16.0 & 1.74 & 13.0 & 1.66 & 9.0 & 1.70 & 11.0 & 1.69 & 12.0 & 0.04113 \\
\hline Mei-G2N & 1.65 & 13.0 & 1.61 & 11.0 & 1.67 & 15.0 & $1.74^{*}$ & 14.0 & $1.92 *$ & 10.0 & 1.72 & 13.0 & 0.05000 \\
\hline Mit-G2N & 1.82 & 19.0 & 1.70 & 28.0 & 1.71 & 16.0 & $1.93^{* *}$ & 11.0 & $1.78^{*}$ & 14.0 & 1.78 & 16.0 & 0.08111 \\
\hline
\end{tabular}




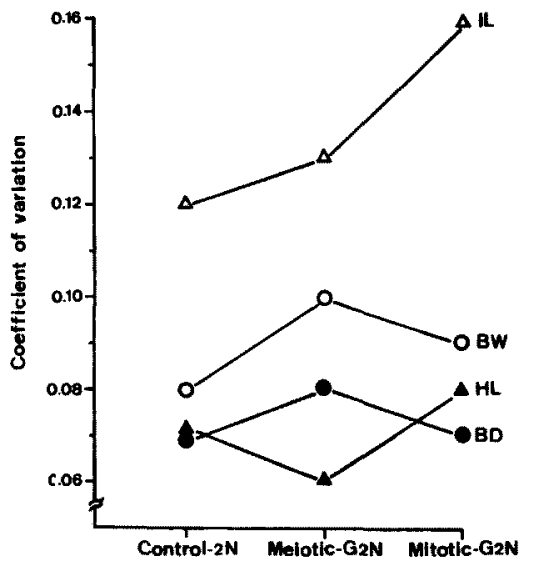

Fig. 1. Comparison of the coefficients of variation among control-2N, meiotic-G2N, and mitotic$\mathrm{G} 2 \mathrm{~N}$ in morphometric characters.
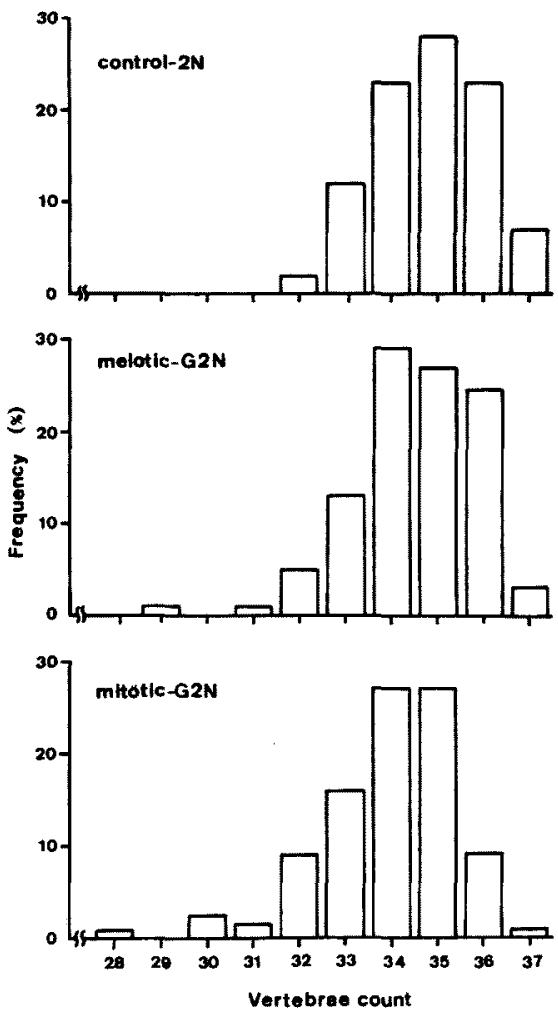

Fig. 2. Comparison of the frequency distribution pattern in vertebral counts among control-2N, meiotic-G2N and mitotic-G2N.

depth, body width and head length of two types of $\mathrm{G} 2 \mathrm{~N}$ were significantly larger than those of control- $2 \mathrm{~N}$ in overall samples. The trends were also observed in respective experimental groups, although some exceptional cases were observed.

The coefficients of variation for the relative intestine length were largest in the mitotic-G2N, smallest in the control-2N and intermediate in the meiotic-G2N in the overall samples. This trend was not observed in the other morphometiric characters (Table 2, Fig. 1).

\section{Variation in Meristic Characters}

Figs. 2 and 3 are examples of histograms of the pooled data of vertebral number and soft dorsal rays from five experiments to compare the distributional patterns of the two types of $\mathrm{G} 2 \mathrm{~N}$ with those of the control-2N. Histograms of the control-2N seemed to be a normal distribution. Distributional patterns of both types of $\mathrm{G} 2 \mathrm{~N}$ were deviated from these of control- $2 \mathrm{~N}$ and seemed to be more flattened in each character. The deviations in meristic count of the two types of G2N from the control-2N were directed to the left or to the smaller number of meristic counts. These
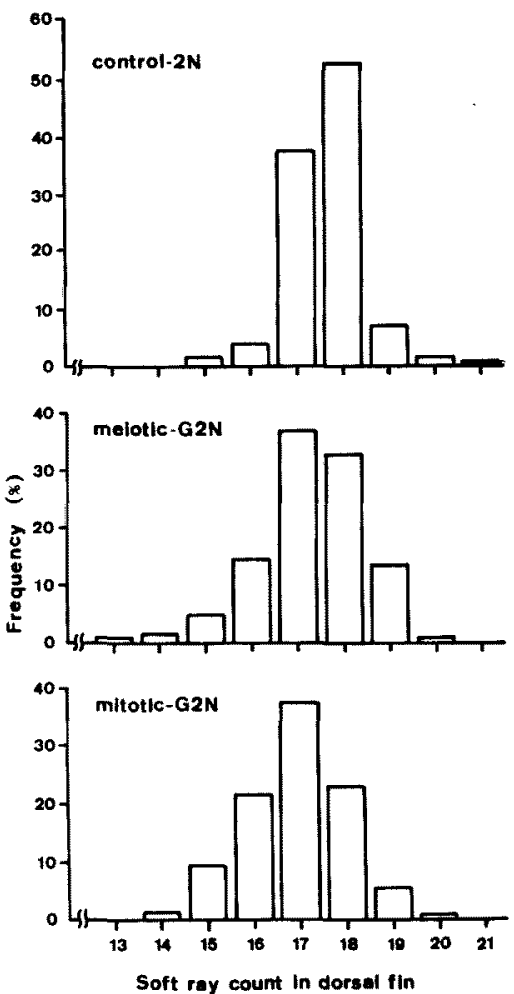

Fig. 3. Comparison of the frequency distribution pattern in soft ray counts of dorsal fin among control-2N, meiotic-G2N and mitotic G2N. 
Table 3. Mean and coefficient of variation of meristic characters in the control-2N, meiotic-G2N, and mitotic-G2N of 5 experiments

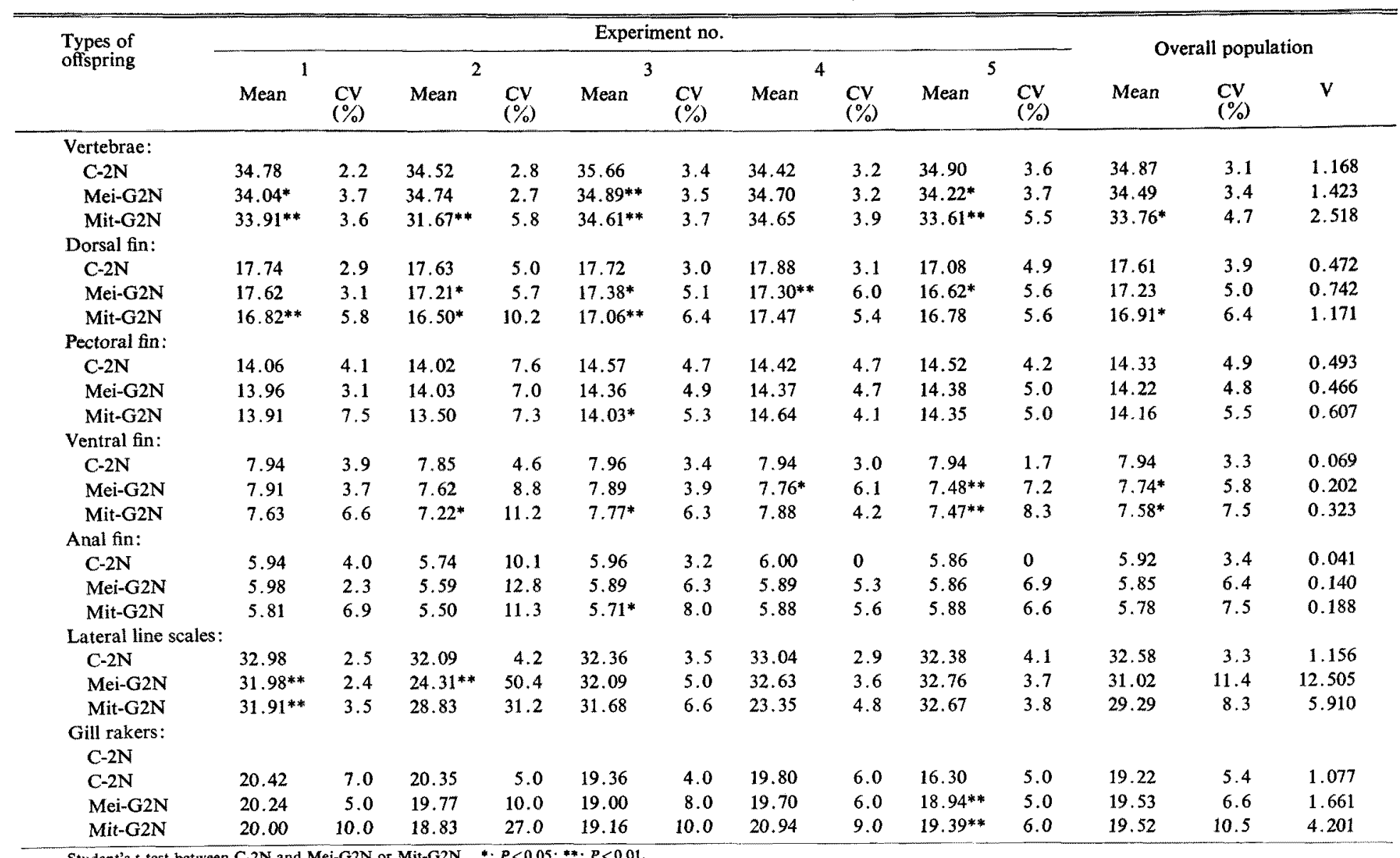




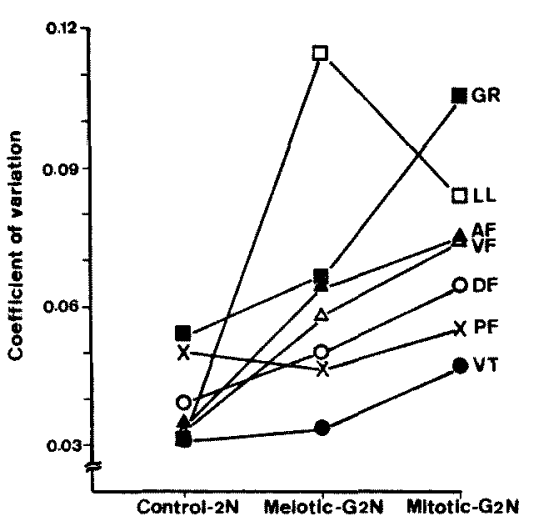

Fig. 4. Comparison of the coefficient of variation values of control- $2 \mathrm{~N}$, meiotic-G2N and mitotic$\mathrm{G} 2 \mathrm{~N}$ in meristic characters.

distributional patterns in the two types of $\mathrm{G} 2 \mathrm{~N}$ being more flattened than the control- $2 \mathrm{~N}$ were observed in all of the meristic characters examined in this study.

Table 3 shows mean counts and the coefficients of variation of meristic characters in the control- $2 \mathrm{~N}$ and the two types of G2N. Mean values of some meristic characters of the two types of $\mathrm{G} 2 \mathrm{~N}$ were not significantly different from the control$2 \mathrm{~N}$. The significant decreases in the mean value were observed in a few characters of G2Ns; these are vertebral counts and numbers of in rays. On the other hand, a significant increase in mean value was observed in gill raker counts of the G2Ns (Ex. 5).

Values of the coefficient of variation (CV) in meristic counts in overall samples were highest in the mitotic-G2N, lowest in the control-2N and intermediate in the meiotic-G2N with some exceptional cases (Fig. 4). These trends observed in the $\mathrm{CV}$ values of the meristic counts were more prominent than those of morphometric characters. These similar trends were also observed in each experiment. An exceptional case from the trend was observed in the counts of lateral line scales of the overall samples (Table 3).

The phenotypic variance $(\mathrm{Vp})$ values of the mitotic-G2N were less than double of control-2N in the most morphometric characters and more than double of control-2N in the most meristic characters of overall samples with some exception (Tables 2 and 3).

\section{Discussion}

In the 1st generation of gynogenesis, genetic variation in the quantitative characters of overall samples is generally expected to expand as an effects of segregation of genotypes, but it is reduced in the second generation of gynogenesis.") The phenomenon of expansion of variation has actually been observed in the 1st generation of G2N populations in ayu. This phenomenon is well explained by the formula of phenotypic variance in G2Ns as follows: $\mathrm{Vp}=\mathrm{Vg}(1+\mathrm{F})+\mathrm{Ve}$ for meiotic-G2N, and $\mathrm{Vp}=2 \times \mathrm{Vg}+\mathrm{Ve}$ for mitoticG2N. ${ }^{\mathrm{s})}$

As mentioned above, the fish examined here were reared under the same condition and same density using same sized concrete tanks with a double bottom and airlift system. Therefore, the environment condition given for each experimental group is considered to be the same, so that the effect of environmental conditions on morphological characters are equivalent principally for each experimental group. Differences between G2ns and control-2N in the level of coefficients of variation were well explained by the formula cited above. The trend that the level of variation is highest in mitotic-G2N, and lowest in control$2 \mathrm{~N}$ and intermediate in meiotic-G2N, was prominent in the meristic characters examined here. On the other hand, this trend was not so distinctly observed in the morphometric characters except by relative intestine length. According to the formula of phenotypic variance in G2Ns, it is suggested that the level of genetic variances for these morphometric characters are very low comparing with those of meristic characters and relative length of intestine examined.

Concerning to the mean values, the differences between G2Ns and control-2N can not be explained by the formula of phenotypic variance for the 1st generation of G2Ns cited above. The present data show a slight increase in the means of body proportions, but a decrease in the means of meristic counts from the control-2N to the meioticG2N and mitotic-G2N in the three month old fish. These changes in distributional pattern shown in Fig. 3 for examples also observed in the other meristic counts as "left direction effects". These changes in the mean values of morphometric and meristic characters suggest the presence of the effect of deleterious genes predicted in the inbreeding line.

Even though phenotypic variances in quantitative characters of meiotic- and mitotic-G2N increased, the level of expansion of variance must be less than double of the variance value of the control-2N as expected by the formula cited above. 
However, the present study as well as study on $\mathrm{ayu}^{\mathrm{g})}$ showed that the variance values of the most quantitative characters in the first generation of two types of G2Ns were far larger than the control$2 \mathrm{~N}$ (Table 3). These very large values of variance in carp and ayu may also suggest the effect of a deleterious gene on the variance of meristic characters of G2Ns as well as segregation of genotypes in polygenic characters.

Among the morphological characters examined in the present study, the lateral line scale and gill raker counts of experiment 2 and 3 showed the drastic increase of variance. These great increases of variance in lateral line scale counts were probably caused by the appearance of about $18 \%$ mirror carp of scattered type in the G2N offspring. The mirror carp of the scattered type may be segregated from the female parent having Ssnn genotype (scaled) for scale control. The large variance of gill rakers of experiment 2 and 3 may also be caused by the segregation of genes of mirror carp. The mirror carp commonly have lower number of gill rakers compared to the scaled type. ${ }^{13)}$

Differences between morphometric and meristic counts in the degree of expansion of variation in the first generation of two types of G2N may be due to the different level of heritability in these characters in the original population.

The genetic background of fish samples used for induction of G2Ns may also give an effect on the degree of increase of variation in the 1st generation of G2Ns. The spawners of ayu used for induction of the G2Ns were collected from the wild population which may include a wide range of variation with a low level of deleterious genes. On the other hand, the Indonesian common carp is domesticated and selected for very long years, so that the level of genetic variation may become low within the stocks and the deleterious genes may have also been already removed through domestication. The difference between fish species or fish races in the degree of increase of variation in the 1st generation of G2Ns should be well investigated.

The present study of phenotypic variation of quantitative characters in the two types of G2N gave evidence to the theory showing the relationship between $F$ value and phenotypic variance in the two types of $\mathrm{G} 2 \mathrm{~N}$ mentioned above as well as the effects of inbreeding. Since the 1st genera- tion of G2Ns are heterogenious and may include deleterious genes as suggested by the coefficients of variation in quantitative characters, the direct application of $\mathrm{G} 2 \mathrm{~N}$ offspring to practical pond culture is not reasonable and appropriate. It is important that the $\mathrm{G} 2 \mathrm{~N}$ offsprings are more profitable as the parents to get effective selection responses in the 2 nd generation of meiotic-G2N or to produce clonal populabtions as the 2 nd generation of the mitotic-G2N as already pro duced in ayu.* The authors will try to produce the second generation of gynogenetic offsprings to fix good traits and to establish useful colonal populations from the selected breeders of the 1 st generation of $\mathrm{G} 2 \mathrm{Ns}$.

\section{Acknowledgements}

We would like to thank Dr. K. Sumawidjaya for his valuable cooperation and suggestions. We thank also Ms. Sri Retno cs. for their excellent technical assistance during the experiments. This work was supported by the International Foundation for Science (IFS), Sweden, grant no. A/542 and the Ronpaku programme of the Japan Cooperation for the Promotion of Science (JSPS), Japan.

\section{References}

1) F. W. Allendorf, J. E. Seeb, K. L. Knudsen, G. H. Thorgaard, and R. F. Leary: J. Heredity, 77(5), 307-312 (1988).

2) R. Guyomard: Theor. Appl. Genet., 67, 307316 (1984).

3) G. Streisinger, C. Walker, N. Dower, D. Knauber, and F. Singer: Nature, 291, 293-296 (1981)

4) D. Chourrout: Aquaculture, 36, 111-126 (1984).

5) N. Taniguchi: in "Chromosome manipulation and its application for aquaculture" (ed. by R. Suzuki), Koseisha Kouseikaku, Tokyo, 1990, pp. $104-117$.

6) F.W. Allendorf and R. F. Leary: Aquaculture, 43, 413-420 (1988).

7) M. Kimura: An Introduction to Population Genetics, 2nd Ed., Baifuukan, Tokyo, 1965, pp. $1-53$.

8) N. Taniguchi, H. Hatanaka, and S. Seki: $A q-$ uaculture, 85, 223-233 (1990).

9) N. Taniguchi, A. Kijima, T. Tamura, K. Takegami, and I. Yamasaki: Aquaculture, 57, 321328 (1986).

10) M. G. Hollebecq, D. Chourrout, G. Wohlfarth

* Taniguchi et al.: Abstract of the annual meeting of the Nippon Suisan Gakkaishi, Tokyo, April 1990, p. 54 . 
and R. Billard: Aquaculture, 54, 69-76 (1986).

11) K. Sumantadinata, N. Taniguchi, and K. Sugama: in "Proc. 2nd Asian Fisheries Forum" (ed. by R. Hirano and I. Hanyu). The Asian Fish. Soc., 1990, pp. 539-542.

12) S. Spotte: Fish and invertebrate culture: Water management in closed systems, 2nd Ed., Jonh Willey and Sons Inc., New York, 1979, pp. 74-78.

13) V. Kirpichnikov: Genetic Bases of Fishes Selection, Springer-Verlag, Berlin and New York, 1981, pp. 45-76. 